\title{
The frequency of GSTT1 null genotype in Turkish population and lung cancer risk
}

\author{
A. Demir, S. Altin ${ }^{1}$, I. Demir ${ }^{1}$, V. Koksal' ${ }^{2}$ U. Cetincelik ${ }^{2}$, S. I. Dincer \\ Departments of Thoracic Surgery, ${ }^{1}$ Chest Disease, Yedikule Teaching Hospital for Chest Diseases and Thoracic Surgery, ${ }^{2}$ Department of \\ Genetics, Sisli Etfal Teaching Hospital, Istanbul, Turkey
}

BACKGROUND: Previous studies have suggested that Glutathione S-transferase (GST) genotypes may play a role in determining susceptibility to lung cancer, though the data are often conflicting. In different ethnic groups variations in null allele frequency has been observed.

AIMS: We aimed to evaluate whether genetic polymorphisms of Glutathione S-transferase theta (GSTT1) influence individual susceptibility to lung cancer in Turkish population. We tried to clarify the frequencies of GSTM1 gene polymorphisms in a Turkish population.

METHODS: DNA samples, extracted from the whole blood were amplified using polymerase chain reaction (PCR) method in all of the 68 cases, composed of 31 previously diagnosed lung cancer and 37 healthy controls.

RESULTS: The prevalence of GSTT1 null genotype in the lung cancer patients was $29 \%$, compared to $11 \%$ in control group. GSTT1 null genotype was found to be higher in cancer group compared to the control group, although it was not statistically significant $(\mathrm{OR}=3.37,95 \% \mathrm{Cl}=0.92$ $12.32, P=0.06)$. There was also no significant relation in GSTT1 genotypes among histopathology types of lung cancers. The frequency of GSTT1 was found to be $25.4 \%$ ( $n=952$ ) when the studies of Turkish population were reviewed.

CONCLUSION: It can be concluded that carrying the GSTT1 null genotype may be accepted as a weak risk factor for the susceptibility to lung cancer.

Key words: Genetic polymorphism; GSTT1 and molecular epidemiology; lung cancer.

Lung cancer is the most common malignancy and the leading cause of cancer death in men world wide and also the second most lethal cancer in women after breast cancer. ${ }^{[1],[2]}$ Active and passive smoking, various occupational exposures, and carcinogens in heavily polluted air are reported to be related to lung cancer in humans. These environmental carcinogens are strongly influenced by individual susceptibility factors. ${ }^{[3]}$ Several genes related with the enzymes involved in metabolic activation and detoxification of pulmonary carcinogens such as polycyclic aromatic hydrocarbons (PAH) and aromatic amines are known to be polymorphic in humans. Individual differences in the ability to activate and detoxify carcinogens are expected to affect the risk of developing lung cancer. ${ }^{[4]}$

Polymorphisms in the genes, encoding phases-I and -Il xenobiotic metabolizing enzymes, have been shown to be associated with susceptibility to lung cancer in a number of epidemiologic studies. ${ }^{[5]}$ However, most of these studies are limited by lack of adequate statistical power. To overcome this limitation, the international collaborative study on genetic susceptibility to environmental carcinogens (GSEC) has been initiated in 1999 and is on-going to pool raw data of studies on metabolic genetic polymorphisms and cancer risk. ${ }^{[6]}$ Environmental xenobiotics, especially cigarette smoke contains several thousands of chemicals, of which about 50 compounds are known to be carcinogens, including PAHs, aromatic amines, and $\mathrm{N}$-nitroso compounds. Most of these compounds are reported to be procarcinogens activated by phase-I enzymes such as those encoded by the CYP supergene family and converted into reactive carcinogens in human body. All these reactive carcinogens can bind to DNA and form DNA adducts capable of inducing mutation and initiating carcinogenesis. 
Glutathione S-transferase enzymes (GSTs) play an important role in the cellular defense mechanism since they are involved in the detoxification and the excretion of environmental pollutants including many carcinogens and also in protection against oxidative stress. ${ }^{[7],[8]}$ Glutathione S-transferase theta (GSTT1) null genotype has been shown to be $11-18 \%$ in Caucasians. ${ }^{[9]}$ No relation between GSTT1 genotype and lung cancer risk has so far been observed, but the presence of both GSTM1 and GSTT1 null genotypes were reported to be associated with increased lung cancer risk. ${ }^{[10],[11]}$

The risk of lung cancer is expected to be monitored by genetic studies using specific biomarkers. Thus, significant findings in specific gene polymorphisms may explain the important mechanisms of susceptibility to lung cancer and provide us the advantage of informing the patients for the potential risks of being exposed to some environmental factors (smoking, air pollution, food, drug, etc.), which are important at least as much as our genetic structure in cancer pathogenesis. Moreover, there may be a chance of taking necessary medical precautions for physicians in earlier stages of lung cancers.

The aim of the present study was to evaluate whether genetic polymorphisms of GSTT1 influence individual susceptibility to lung cancer in Turkish population. Thus, we aimed at clarifying the frequencies of GSTM1 gene polymorphisms in a Turkish population.

\section{Materials and methods}

\section{Study subjects and sample collection}

A total 68 subjects, composed of 31 lung cancer patients who attended Yedikule Teaching Hospital for Chest Diseases and Thoracic Surgery in Istanbul between 2000 and 2002 and 37 health controls, were included in this study. The sample size was chosen according to detect any clinically significant difference between the groups and also to the availability of costly molecular methods. All cancer patients and controls were born in Turkey. The control group had none of any cancers or chronic diseases. The mean ages were found to be $55 \pm 10$ (range 30-72) and $34 \pm 11$ (range 20-65) in cancer group and healthy controls, respectively. About 28 patients in 31 lung cancer patients and 9 subjects in 37 cancer-free groups were smokers. This study was approved by local hospital ethics committee on human research. All patients gave informed consent.

\section{GSTT1 genotyping}

Peripheral blood samples, collected from lung cancer patients and control subjects and DNA extraction was performed using peripheral EDTA-blood samples by a commercial DNA isolation kit (Qiagen, Hilden, Germany). DNA samples were amplified with the primers: 5TCACCGGATCATGGCCAGCA-3 and 5TTCCTTACTGGTCCTCACATCTC-3 for GSTT1, which produced a 459 bp product. ${ }^{[12]}$ Amplification of globin gene was used as an internal control and produced a $522 \mathrm{bp}$ product. The PCR amplification was carried out $1 \mathrm{mg}$ DNA in $10 \mathrm{mM}$ Tris- $\mathrm{HCl}$, $\mathrm{pH} 8.3,50 \mathrm{mM} \mathrm{KCl}, 3 \mathrm{mM} \mathrm{MgCl}$, $0.3 \mathrm{mM}$ deoxyribonucleotide triphosphates (Fermentas), $0.2 \mathrm{mM}$ of each primer and $1.5 \mathrm{U}$ of Taq polymerase (Fermentas) in a total volume of $50 \mathrm{ml}$. Amplification was performed with initial denaturation at $94^{\circ} \mathrm{C}$ for $5 \mathrm{~min}$, followed by 30 cycles at $94^{\circ} \mathrm{C}$ for $1 \mathrm{~min}, 61^{\circ} \mathrm{C}$ for $1 \mathrm{~min}$, $72 \mathrm{C}$ for $1 \mathrm{~min}$, and a final extension at $72 \mathrm{C}$ for $10 \mathrm{~min}$, using a MJ Research PTC160 thermal cycler.

The amplification product ( $10 \mu \mathrm{l})$ was visualized in an ethidium bromide stained $1.5 \%$ agarose gel. All the genotype determination were carried out twice in independent experiments and all the inconclusive samples were reanalyzed. The results of GSTT genotyping were documented as shown in [Figure 1].

\section{Statistical analysis}

Statistical analyses were performed using the Statistical Package for the Social Sciences Program (SPSS, Version 10). Pearson's $x 2$ test was used to examine differences with regard to demographic

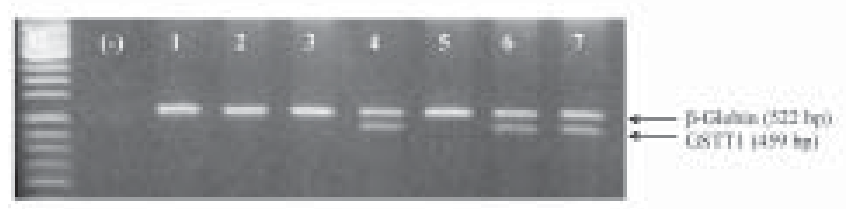

Figure 1: GSTT1 genotyping. (-): Water; 1, 2, 3, and 5 patients: GSTT1 null genotype (0/0); 4, 6, and 7 patients: GSTT1 +/+ or \pm genotype. M: 100 bp ladder size marker 
variables, smoking, and distribution of genotypes. Associations between the GSTT1 polymorphisms and risk of lung cancer were estimated using odds ratios (ORs) and 95\% confidence intervals (95\% Cls) calculated by conditional logistic regression.

\section{Results}

Relevant demographic characteristics of the study subjects were documented in [Table 1]. GSTT1 $(+/+$ or $+/ 0)$ or GSTT1 $(0 / 0)$ genotypes were determined to be $22(71 \%)$ and $9(29 \%)$ of lung cancer patients, respectively. In the control group, GSTT1 $(+/+$ or $+/ 0)$ and GSTT1 (0/0) genotypes were found to be $33(89 \%)$ and $4(11 \%)$, respectively. Although it was not statistically significant, GSTT1 (0/0) null genotype was found to be higher in cancer group compared with the control group $(\mathrm{OR}=3.37,95 \% \mathrm{Cl}=0.92-12.32, P=$ 0.06) [Table 2].

Histopathological evaluation, performed according to WHO criteria, revealed that epidermoid carcinoma (EPCA), adenocarcinoma (ACA), large-cell carcinoma (LCA), small-cell carcinoma (SCCA), and nonsmall-cell carcinoma (NSCCA) were present in $48.4 \%(n=15)$, $12.9 \%(n=4), 6.4 \%(n=2), 9.7 \%(n=3)$, and $22.6 \%$ $(n=7)$ out of 31 lung ca patients, respectively. Although there was no statistically significant difference among the histopathologic types of lung cancer, OR was

Table 1: Demographic characteristics of the lung cancer patients and controls

\begin{tabular}{lcc}
\hline Characteristics & Patients $(\boldsymbol{n}=\mathbf{3 1})$ & Controls $(\boldsymbol{n}=\mathbf{3 7})$ \\
\hline Mean & 5510 & $34 \pm 11$ \\
Range & $(30-72)$ & $(20-65)$ \\
Male & 29 & 24 \\
Female & 2 & 13 \\
Smokers & 28 & 9 \\
Nonsmokers & 3 & 28 \\
Cigarettes (package/year) & $39.2 \pm 3.2$ & $14.5 \pm 3.2$ \\
\hline
\end{tabular}

Table 2: Frequency of GSTT1 genotypes in lung cancer patients and controls

\begin{tabular}{lcccc}
\hline Genotypes & Patients & Control & OR $(95 \% \mathrm{Cl})$ & $\boldsymbol{P}$ value \\
\hline GSTT1 & & & & \\
Present & $22(71 \%)$ & $33(89 \%)$ & 1.0 & \\
Null & $9(29 \%)$ & $4(11 \%)$ & $3.37(0.92-12.32)$ & 0.06 \\
\hline
\end{tabular}

determined to be $0.62(95 \% \mathrm{Cl}=0.16-3.79)$ and 2.85 (0.33-24.29) for EPCA and ADC, respectively. No statistically significant relationship was found between genetic polymorphisms and the smoking status of all the subjects $(P>0.05)$.

\section{Discussion}

A number of studies have tried to establish links between polymorphic expression of different GSTs and lung cancer risk in different ethnic populations, ${ }^{[13-16]}$ and the results have been conflicting. ${ }^{[13],[17]}$ One reason for the discrepancies could be the fact that most studies were conducted in different populations. However, none of the main characteristics of the subjects explain satisfactorily the apparent discrepancies (i.e, race, histological type, and level of smoking). Different histological subtypes of lung cancer, in particular may also be related to respective exposures or factors, and thus need to be analyzed separately. ${ }^{[13],[18]}$

Several Caucasian studies were previously conducted to assess the role of GSTT1 in lung cancer susceptibility with the case-control approach. ${ }^{[10],[11],[19-22]}$ No significant associations of GSTT1 with lung cancer risk could be established, and two of the studies found that the GSTT1 null genotype did not elevate the risk with either lung adenocancer or squamous cell carcinoma. ${ }^{[19],[20]}$ Another study in Chinese found that the GSTT1 genotype was not related to lung cancer. ${ }^{[23]} A$ recent study in Japanese provided evidence that the GSTT1 null genotype is a risk factor for lung cancer development. ${ }^{[24]}$ In another case-control study in the United States among AfricanAmericans (Black) and Mexican-Americans (Hispanics) demonstrated a significant relationship of the GSTM1 null genotype with lung cancer in Mexican-Americans, but no statistically significant association of the GSTT1 null genotype was found for either ethnic group. ${ }^{[25]}$ In our study, OR of GSTT1-null genotype was found to be 3.5 compared with healthy controls, although it was not statistically significant $(P=0.06)$. Moreover, concordant with the studies of Saarikoski et al. ${ }^{[19]}$ and Risch et al, ${ }^{[20]}$ no significant relation between histopathological types of lung cancers and GSTT1 null genotype was detected in our study. These findings, obtained in Turkish population, reveals that further studies containing larger 
number of subjects should be performed to investigate this relationship between GSTT1 null genotype and lung cancer.

The incidence of the GSTT1 gene deletions differs among ethnic groups. The prevalence of GSTT1 null genotype has been shown to be $11-18 \%$ in Caucasians. ${ }^{[9-11]}$ Taioli et al. ${ }^{[6]}$ reported that GSTT1 null genotype was detected to be $17 \%$ in Caucasians. The incidence of the GSTT1 gene deletions in healthy controls in Koreans was significantly higher (45.3\%) compared to those of white Americans (20.4\%), AfricanAmericans (21.8\%), and Mexican-Americans $(9.7 \%) .^{[26],[27]}$ In our study with Turkish population subjects, the incidence of GSTT1 deletion in healthy controls was significantly lower (10.8\%) compared to those of other studies (17.3-28.3\%) in Turkish population. ${ }^{[28-34]}$ Overall, the GSTT1 null genotype was found to be higher (25.4\%) among the Turkish populations as compared to European but lower than Singapore, Japan, and Korea. ${ }^{[35]}$

We can conclude that carrying the GSTT1 null genotype may be accepted as a weak risk factor for the susceptibility to lung cancer. In future, the risk of lung cancer is expected to be monitored using specific biomarkers in genetic researches. Large-scale multicentric studies are necessary to obtain more reliable and correct results.

\section{References}

1. Parkinm DM, Pisani P, Ferlay J. Global cancer statistics. CA Cancer J Clin 1999;49:33-64.

2. Ferlay J, Bray F, Pisani P, Parkin DM. Cancer Incidence, Mortality and Prevalance Worlwide (1.0), CancerBase no.5. IARC, Lyon, France. 2001 GLOBOCAN 2000

3. Perera FP. Molecular epidemiology of environmental carcinogenesis. Recent Results Cancer Res 1998;154:39-46.

4. Raunio H, Husgafvel-Pursiainen K, Anttila S, Hietanen E, Hirvonen A, Pelkonen O. Diagnosis of polymorphisms in carcinogen-activating and inactivating enzymes and cancer susceptibility. Gene 1995;159:113-21.

5. Strogn LC, Amos CI. Inherited susceptibility. In Schottenfeld D, Searle JG and Fraumeni JF (Eds). Cancer Epidemiology and Prevention. Oxford University Press: NewYork; 1996. p. 559-82.

6. Taioli E, Gaspari L, Benhamou S, Boffetta P, Brockmoller J, Butkiewicz D, et al. Polymorphisms in CYP1A1, GSTM1, GSTT1 and lung cancer below the age of 45 years. Int J Epidemiol 2003;32:60-3.

7. Hayes JD, Pulford DJ. The glutathione S-transferase supergene family: regulation of GST and the contribution of the isoenzymes to cancer chemoprotection and drug resistance. Crit Rev Biochem Mol Biol 1995;30;445-600.

8. Strange RC, Fryer AA. The glutathione S-transferases: influence of polymorphism on cancer susceptibility. IARC Sci Publ 1999;148;231-49.

9. Rebbeck TR. Molecular epidemiology of the human glutathione S-transferase genotypes GSTM1 and GSTT1 in cancer susceptibility. Cancer Epidemiol Biomarkers Prev 1997;6:733-43.

10. Deakin M, Elder J, Hendrickse C, Peckham D, Baldwin D, Pantin C, et al. Gluthione S-transferase GSTT1 genotypes and susceptibility to cancer: studies of interactions with GSTM1 in lung, oral, gastric and colerectal cancers. Carcinogenesis 1996;17:881-4

11. Jourenkova N, Reinikanen M, Bouchardy C, HusgafvelPursiainen K, Dayer P, Benhamou S, et al. Effects of glutathione S-transferases GSTM1 and GSTT1 genotypes on lung cancer risk in smokers. Pharmacogenetics 1997;7:515-8.

12. Teixeira JP, Gaspar J, Martinho G, Silva S, Rodrigues S, Mayan O, et al. Aromatic DNA adduct levels in coke oven workers: correlation with polymorphisms in genes GSTP1, GSTM1, GSTT1 and CYP1A1. Mutat Res. 2002;517:14755.

13. Wang J, Deng Y, Cheng J, Ding J, Tokudome S.GST genetic polymorphisms and lung adenocarcinoma susceptibility in a Chinese population. Cancer Lett 2003;201:185-93.

14. Ryberg D, Skaug V, Hewer A, Phillips DH, Harries LW, Wolf CR, et al. Genotypes of glutathione transferase M1 and $\mathrm{P} 1$ and their significance for lung DNA adduct levels and cancer risk. Carcinogenesis 1997;18;1285-9.

15. Kihara M, Kihara M, Noda K. Lung cancer risk of the GSTM1 null genotype is enhanced in the presence of the GSTP1 mutated genotype in male Japanese smokers. Cancer Lett 1999;137:53-60.

16. Jourenkova-Mironova N, Wikman $\mathrm{H}$, Bouchardy C, Voho A, Dayer P, Benhamou S, et al. Role of glutathione Stransferase GSTM1, GSTM3, GSTP1 and GSTT1 genotypes in modulating susceptibility to smoking-related lung cancer. Pharmacogenetics 1998;8:495-502.

17. Hayes JD, Strange RC. Glutathione S-transferase polymorphisms and their biological Consequences. Pharmacology 2000;61:154-66.

18. Le Marchand L, Sivaraman L, Pierce L, Seifried A, Lum A, Wilkens LR, et al. Associations of CYP1A1, GSTM1, and CYP2E1 polymorphisms with lung cancer suggest cell type specificities to tobacco carcinogens. Cancer Res 1998;58:4858-63.

19. Saarikoski ST, Voho A, Reinikainen M, Anttila S, Karjalainen A, Malaveille C, et al. Combined effect of polymorphic GST genes on individual susceptibility to lung cancer. Int J Cancer 1998;77:516-21.

20. Risch A, Wikman H, Thiel S, Schmezer P, Edler L, Drings $\mathrm{P}$, et al. Glutathione-S-transferase M1, M3, T1 and P1 polymorphisms and susceptibility to non-small-cell lung cancer subtypes and hamartomas. Pharmacogenetics 2001;11:757-64.

21. Salagovic J, Kalina I, Stubna J, Habalova V, Hrivnak M, Valansky L, et al. Genetic polymorphism of glutathione S-transferases $\mathrm{M} 1$ and $\mathrm{T} 1$ as a risk factor in lung and bladder cancers. Neoplasma 1998;45:312-7.

22. To-Figueras J, Gene M, Gomez-Catalan J, Galan MC, 
Fuentes M, Ramon JM, et al. Glutathione S-transferase M1 (GSTM1) and T1 (GSTT1) polymorphisms and lung cancer risk among Northwestern Mediterraneans. Carcinogenesis 1997;18:1529-33.

23. Sun GF, Shimojo N, Pi JB, Lee S, Kumagai Y. Gene deficiency of glutathione S-transferase $\mathrm{mu}$ isoform associated with susceptibility to lung cancer in a Chinese population. Cancer Lett 1997;113:169-72.

24. Sunaga N, Kohno T, Yanagitani N, Sugimura H, Kunitoh $\mathrm{H}$, Tamura T, et al. Contribution of the NQO1 and GSTT1 polymorphisms to lung adenocarcinoma susceptibility. Cancer Epidemiol Biomarkers Prev 2002;11:730-8.

25. Kelsey KT, Spitz MR, Zuo ZF, Wiencke JK. Polymorphisms in the glutathione S-transferase class mu and theta genes interact and increase susceptibility to lung cancer in minority populations (Texas, United States). Cancer Causes Control 1997;8:554-9.

26. Nelson HH, Wiencke JK, Christiani DC, Cheng TJ, Zuo ZF, Schwartz BS, et al. Ethnic difference in the prevalence of the homozygous deleted genotype of glutathione Stransferase. Carcinogenesis 1995;16:1243-5

27. Lee KA, Kim SH, Woo HY, Hong YJ, Cho HC. Increased frequencies of glutathione S-transferase (GSTM1 and GSTT1) gene deletions in Korean patients with acquired aplastic anemia. Blood 2001;98:3483-5.

28. Tamer L, Calikoglu M, Ates NA, Yildirim H, Ercan B, Saritas E, et al. Glutathione-S-transferase gene polymorphisms (GSTT1, GSTM1, GSTP1) as increased risk factors for asthma. Respirology 2004;9:493-8.
29. Özbek U, Aydýn M, Hatýrnaz A, et al. Metabolising Enzyme Polymorphisms (GSTM1, GSTT1, CYP1A1, CYP2D6) and Their Association as a Potential Susceptibility to Pediatric ALL. American Society of Hematology 43rd Annual Meeting and Exposition: Orlando, FL; 2001.

30. Tamer L, Ercan B, Camsari A, Yildirim H, Cicek D, Sucu $\mathrm{N}$, et al. Glutathione S-transferase gene polymorphism as a susceptibility factor in smoking-related coronary artery disease. Basic Res Cardiol 2004;99:223-9.

31. Ada AO, Suzen SH, Iscan M. Polymorphisms of cytochrome P450 1A1, glutathione S-transferases M1 and T1 in a Turkish population. Toxicol Lett 2004;15:311-5.

32. Oke B, Akbas F, Aydin M, Berkkan H. GSTT1 null genotype frequency in a Turkish population. Arch Toxicol 1998;72:454-5

33. Toruner GA, Akyerli C, Ucar A, Aki T, Atsu N, Ozen H, et al. Polymorphisms of glutathione S-transferase genes (GSTM1, GSTP1 and GSTT1) and bladder cancer susceptibility in the Turkish population. Arch Toxicol 2001;75:459-64.

34. Tursen U, Tamer L, Eskandari G, Kaya TI, Ates NA, Ikizoglu G, et al. Glutathione S-transferase polymorphisms in patients with Behcet's disease. Arch Dermatol Res 2004;296:185-7.

35. Garte S, Gaspari L, Alexandrie AK, Ambrosone C, Autrup H, Autrup JL, et al. Metabolic gene polymorphism frequencies in control populations. Cancer Epidemiol Biomarkers Prev 2001;10:1239-48. 